\title{
ENVIRONMENTAL PLANNING AND MANAGEMENT OF CITIES AND REGIONS - EDITORIAL
}

\author{
DIMITRA VAGIONA
}

Department of Spatial Planning and Development, Aristotle University of Thessaloniki, Thessaloniki, Greece
Corresponding author: dimvag@plandevel.auth.gr

doi: 10.14712/23361964.2016.1

Cities and regions are highly complex systems in terms of spatial organization and function, as well as in terms of governance, management and policy. They are subject to major urban and economic developments, as well as more recent challenges such as climate change, crises in terms of energy, food and funding, and increasing environmental vulnerability. Appropriate planning and management not only has to accommodate future urban growth but also guarantee environmental sustainability.

This Special Feature in the first part of this issue of the European Journal of Environmental Sciences on Environmental Planning and Management for cities and regions contains six papers on the following issues: urban sustainability policies, urban mobility plans, environmental effects of traffic management strategies, environmental pollution due to road traffic, water saving in tourist units and green tourism supply chain management.

The first paper introduces and depicts a way of setting and managing policy priorities in urban planning. Urban planning addresses the needs and capacities of a city using a multidisciplinary scientific and political process, which regulates urban development taking into account other components of the urban environment. Decision support tools are essential for developing urban strategies for cities, which involves all those who live, work, invest and use all the facilities in a city, as well as visitors and many others.

One of the most important components of an urban environment is transport. Three contributions on this special feature address transportation and sustainable mobility.

Appropriate planning of transport could increase the degree of its sustainability for societies and local authorities. Traditional planning of urban transport reacts to the increasing demand for improved mobility by constantly increasing the infrastructure; whereas sustainable urban mobility planning provides a more holistic approach that aims to maximize the efficiency of the transport system and minimize environmental degradation. Land Use and Transport Interaction models should be integrated into all phases of the Sustainable Urban Mobility Planning process and used to analyze, synthesize and test alternative mobility plans as part of the sustainable spatial planning process and decision making.
Moreover, it is important to evaluate the environmental effects of traffic management schemes and pedestrianization in an urban area. Traffic congestion in urban areas results in increased energy consumption and vehicle emissions. Although pedestrianization aims to promote awareness of the historic environment of cities, it results in an increase in fuel consumption and emissions. Sustainable transport systems limit polluting emissions, waste, etc. and attempt to ensure that the planet's ability to absorb these pollutants is not exceeded. Traffic management plans that not only alleviate traffic congestion but also mitigate the environmental effects of vehicular traffic are necessary.

In terms of global fuel combustion and the related $\mathrm{CO}_{2}$ emissions the transport sector accounts for an estimated $23 \%$, of which almost three-quarters is attributed to road traffic. Although the road traffic sector is the main emitting source in urban areas, there is a growing concern about the consequences of wildfires in peri-urban forests. It is of utmost importance to investigate and integrate into environmental models the effects of forest fires on carbon emissions, air pollution, biodiversity and climate change dynamics. There is an interesting contribution in this special issue on a joint analysis of the pollutants produced by road transport in a city and the reduction of the carbon sequestration capacity of regional forests around the city before and after wild fires.

The last two papers are on the tourism sector, which is considered one of the most dynamic and far-reaching economic sectors in the world. Apart from a key driver for socio-economic progress, tourism can be responsible for the environmental deterioration of tourist areas, as tourist activities often exert great pressure on natural and anthropogenic environments. Both papers focus on the accommodation sector. Hotels cause significant environmental stress in both natural and urban environments due to their high consumption of water and energy. In addition, the production of large volumes of liquid and solid wastes have a very significant effect on the environment. The aim of the first paper is to assess the environmental performance of mid-sized hotel units by analyzing and quantifying their use of water in order to develop a means of achieving a sustainable consumption. The last paper presents a robust methodological approach for developing Green Tourism Supply Chain Management 
(GTSCM) in the hospitality sector, based on estimates of the environmental effect that can be attributed to each link in the supply chain. It is proposed that Life Cycle Analysis (LCA) and Life Cycle Thinking (LCT) should form the basis for efficiently promoting GTSCM in the tourism industry. If the proposed methodology is used properly and consciously by the hotel industry, it will not only help hotel companies improve their efficiency and reduce costs but also contribute to the greening of TSCM at tourist destinations. 